Please do not remove this page

RMIT

UNIVERSITY

\title{
Aircraft dynamics model augmentation for RPAS navigation and guidance
}

Cappello, Francesco; Sabatini, Roberto; Ramasamy, Subramanian

https://researchrepository.rmit.edu.au/esploro/outputs/9921860486401341/filesAndLinks?institution=61RMIT_INST\&index=null

Cappello, F., Sabatini, R., \& Ramasamy, S. (2016). Aircraft dynamics model augmentation for RPAS navigation and guidance. Proceedings of the IEEE International Conference on Unmanned Aircraft Systems (ICUAS 2016), 457-464.

https://researchrepository.rmit.edu.au/discovery/fulldisplay/alma9921860486401341/61RMIT_INST:Resea rchRepository

Document Version: Accepted Manuscript

Repository homepage: https://researchrepository.rmit.edu.au

(C) 2016 IEEE

Downloaded On 2023/04/27 01:11:21 +1000

Please do not remove this page 
Thank you for downloading this document from the RMIT Research Repository.

The RMIT Research Repository is an open access database showcasing the research outputs of RMIT University researchers.

RMIT Research Repository: http://researchbank.rmit.edu.au/

\section{Citation:}

Cappello, F, Sabatini, R and Ramasamy, S 2016, 'Aircraft dynamics model augmentation for RPAS navigation and guidance', in Proceedings of the IEEE International Conference on Unmanned Aircraft Systems (ICUAS 2016), United States, 7-10 June 2016, pp. 457-464.

See this record in the RMIT Research Repository at:

https://researchbank.rmit.edu.au/view/rmit:37260

Version: Accepted Manuscript

Copyright Statement: (C) 2016 IEEE

Link to Published Version:

http://www.uasconferences.com/index.php 
This is the author pre-publication version. This paper does not include the changes arising from the revision, formatting and publishing process. The final paper that should be used for referencing is:

F. Cappello, R. Sabatini and S. Ramasamy, “Aircraft Dynamics Model Augmentation for RPAS Navigation and Guidance.” Proceedings of IEEE International Conference on Unmanned Aircraft Systems (ICUAS 2016). Arlington, VA (USA), June 2016. Print ISBN: 978-14673-9333-1

\title{
Aircraft Dynamics Model Augmentation for RPAS Navigation and Guidance
}

\author{
Francesco Cappello, Roberto Sabatini, Subramanian Ramasamy \\ School of Engineering - Aerospace, Mechanical and Manufacturing, \\ RMIT University, Melbourne, VIC 300, Australia \\ roberto.sabatini@rmit.edu.au
}

\begin{abstract}
In this paper, Aircraft Dynamics Model (ADM) augmentation for Remotely Piloted Aircraft System (RPAS) navigation and guidance is presented. This approach provides additional information suitable to compensate for the shortcomings of vision based navigation sensors and MicroElectromechanical System Inertial Measurement Unit (MEMS-IMU) sensors for attitude determination tasks. The ADM virtual sensor is essentially a knowledge-based module and is used to augment the navigation state vector by predicting RPAS flight dynamics (aircraft trajectory and attitude motion). The ADM employs a rigid body 6-Degree of Freedom (6-DoF) model and is implemented in integrated multi-sensor data fusion architectures. The integration is accomplished with an Extended Kalman Filter (EKF) and Unscented Kalman Filter (UKF). After introducing the key mathematical models describing the 6-DoF ADM, the sensor and integrated system performance are compared in a small RPAS integration scheme (i.e., AEROSONDE RPAS platform) exploring a representative cross-section of the aircraft operational flight envelope and a preliminary sensitivity analysis is performed. In addition to a centralised filter, a dedicated ADM processor (i.e., a local pre-filter) is adopted to account for the RPAS manoeuvring envelope in different flight phases, in order to extend the ADM validity time across all segments of the RPAS trajectory. Sensitivity analysis of the errors caused by perturbations in the input parameters of the aircraft dynamics is performed to demonstrate the robustness of the proposed approach. Results verify that the ADM virtual sensor provides improved performance in terms of attitude data accuracy and a significant extension of the ADM validity time is achieved by pre-filtering.
\end{abstract}

Keywords-Aircraft Dynamics Model; Virtual Sensor; Knowledge-Based Sesnor, Multi-Sensor Data Fusion.

\section{INTRODUCTION}

The current state-of-the-art in unmanned air, ground and underwater systems supports operations from remote locations. In particular, Remotely Piloted Aircraft System (RPAS) are increasingly used for a variety of civil and military applications as these vehicles provide cost-effective and safe alternatives to manned flights in a range of operational scenarios. RPAS are equipped with necessary sensors, communication processing units, automatic control, and other avionics systems, which allow the platform to perform tasks autonomously without human intervention. Over the past three decades, there has been a significant amount of growth in RPAS avionics systems attributed to advances in micro processing technology, hardware miniaturisation, innovative sensor and multi-sensor fusion technologies [1]. These improvements have resulted in failsafe systems that guarantee a lower probability of failure when compared to manned aircraft [2]. This recent technological advancement has allowed RPAS to be applied to increasingly larger number of applications, including numerous military applications which include surveillance, reconnaissance, communications relays and battle damage assessment. Civil and commercial applications are also being developed, although potential applications are extremely broad in scope, which include environmental monitoring (e.g. pollution and weather), forest fire monitoring, precision agriculture, rural search and rescue and disaster relief. Currently, RPAS operations are specifically undertaken in segregated airspaces. As a result, the International Civil Aviation Organisation (ICAO) has developed Aviation System Block Upgrades (ASBU) to facilitate the integration of RPAS into all classes of airspace by defining standards, procedures, guidelines and roadmaps [3]. Additionally, along with national and regional aviation certification authorities, ICAO has formed working groups to understand, define and integrate RPAS into the next generation Air Traffic Management (ATM) system. Due to the rapid development of technologies, procedures and standards, RPAS are expected to become fully integrated into all classes of airspace [4]. Functional requirements, which drive the RPAS flight management system are intelligent flight planning, guidance, navigation and control, fault monitoring and isolation, Sense-and-Avoid (SAA), sensor management, operating system and software considerations [5]. These functionalities provided by automated guidance services support enhanced navigational capabilities in order to meet the Required Navigational Performance (RNP) and Reduced Vertical Separation Minima (RVSM) levels at all flight phases. Typically, a variety of sensors are employed to derive information about the surrounding environment and aircraft performance in order to provide accurate and continuous knowledge of vehicle states. Typically, avionics sensors including satellite, inertial and vision-based techniques are employed in integrated navigation and guidance system architectures. These systems employ a variety of active and passive navigation sensors, as well as multi-sensor data fusion techniques, in order to provide trusted autonomous 
This is the author pre-publication version. This paper does not include the changes arising from the revision, formatting and publishing process. The final paper that should be used for referencing is:

F. Cappello, R. Sabatini and S. Ramasamy, “Aircraft Dynamics Model Augmentation for RPAS Navigation and Guidance.” Proceedings of IEEE International Conference on Unmanned Aircraft Systems (ICUAS 2016). Arlington, VA (USA), June 2016. Print ISBN: 978-14673-9333-1

operations. More specifically, to satisfy the Required Communication Performance (RCP) and Required Surveillance Performance (RSP), further technological developments are required such as a certified SAA system and, high-integrity and secure Line-of-Sight (LOS) and Beyond LOS (BLOS) data links.

The main objective of this research is to improve the navigation solution by employing an Aircraft Dynamics Model (ADM) virtual sensor. The ADM is adopted as a knowledge-based module to augment the navigation state vector by predicting the RPAS flight dynamics (aircraft trajectory and attitude motion). The novelty of the research is the introduction of ADM that can employ either a three Degree-of-Freedom (3-DoF) or a six Degree-of-Freedom (6-DoF) with suitable controls and constraints applied in different flight phases. To realise the required system performance, the kinematic/dynamic equations of motion and the transformation of forces/moments acting on the RPAS are accurately modelled. Pre-filtering of the ADM virtual sensor measurements is implemented to obtain a reduction in the overall position and attitude error budget, and more importantly to obtain a considerable reduction in the overall ADM re-initialisation time. In addition to developing integrated navigation systems, the data provided by the Guidance, Navigation and Control (GNC) loop are used to optimise the design of a hybrid control system, tailored for VBN, which employs fuzzy logic and Proportional-Integral-Derivative (PID) techniques.

\section{AIRCRAFT DYNAMICS MODEL}

As stated earlier, the ADM can employ either a 6-DoF or a 3-DoF ADM with suitable constraints applied in the different phases of the RPAS flight. The input data required to run these knowledge-based modules are made available from aircraft physical sensors (i.e., aircraft data network stream) and from ad-hoc databases [6, 7].

The selected platform is AEROSONDE RPAS, which is a small autonomous aircraft used in weather-reconnaissance and remote-sensing missions. The AEROSONDE RPAS is capable of extended surveillance and reconnaissance over land and sea in a variety of environmental conditions, delivering real-time information persistently and reliably. It offers an impressive endurance of more than 26 hours (with a minimal payload) [8]. With a full electro-optic/infrared payload, the platform can still achieve endurances in excess of 10 hours. This remarkable endurance, as well as the payload flexibility, modularity and affordability of the aircraft make it an ideal choice for remote data collection and reconnaissance missions for military, civil and scientific entities $[9,10]$. The aircraft employs a catapult system to take-off from small, remote clearings and ships, and can also launch from the roof of a fast-moving ground vehicle. A typical AEROSONDE RPAS includes:

- Mark 4.7 aircraft equipped with a variety of payloads;

- One trailer-mounted combined launch/recovery system;
- Ground Control Station (GCS): STANAG 4586compliant One System Ground Control Station (OSGCS) family;

- Auxiliary/support ground equipment and

Fig. 1 depicts the AEROSONDE RPAS and the reference frame employed for modelling and simulation activities. Body frame of reference is used as the navigation reference frame and is defined as: ' $x$ ' along the longitudinal axis, positive ' $y$ ' as along the right wing and ' $z$ ' as normal to both ' $\mathrm{x}$ ' and ' $\mathrm{y}$ '.

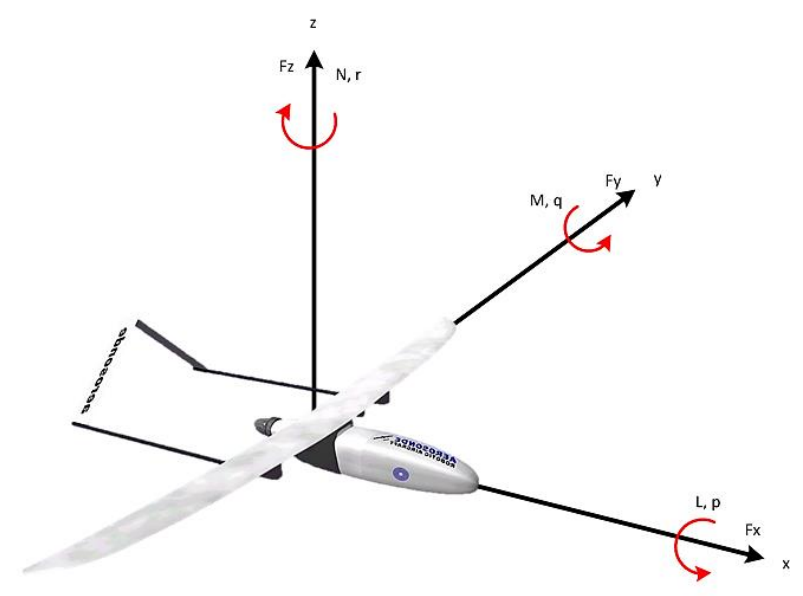

Fig. 1. AEROSONDE RPAS reference frame.

The ADM is modelled using 6-DoF geodetic non-linear equations to describe the forces and moments acting on the aircraft. The motion of the AEROSONDE is described in the body frame $\mathrm{G}$ with:

- Velocity: $V=[u v w]^{T}$ and

- $\quad$ Angular rate: $W=[p q r]$

where $\mathrm{u}$ is the axial velocity, $\mathrm{v}$ is the lateral velocity and $\mathrm{W}$ is the normal velocity, $\mathrm{p}$ is the roll rate, $\mathrm{q}$ is the pitch rate, $\mathrm{r}$ is the yaw rate and $\mathrm{T}$ is the transposition of the matrix. Equations of motion are derived by implementing Newton's second law that deals with vector summations of all forces and moments as applied to the airplane relative to an inertial reference frame. However, for practical reasons, analysis may be significantly simplified if motion is described relative to a body-fixed reference frame attached to the airplane. When this is the case, the equations of motion are derived relative to this non-inertial frame. Further, Euler angles are used to define the airplane orientation relative to a general Earth-fixed inertial frame. The overall assumptions made are: a rigid body RPAS is considered, the aircraft mass is located at the centre of gravity and hence the mass is varying only as a result of fuel consumption, wind effects and sideslip are neglected, and uniform gravity is considered. The geodetic coordinate system of reference used is World Geodetic System of year 1984 (WGS 84). The uncertainties in the aerodynamic parameters are the primary source of errors in the model. The accuracy of these 
This is the author pre-publication version. This paper does not include the changes arising from the revision, formatting and publishing process. The final paper that should be used for referencing is:

F. Cappello, R. Sabatini and S. Ramasamy, “Aircraft Dynamics Model Augmentation for RPAS Navigation and Guidance.” Proceedings of IEEE International Conference on Unmanned Aircraft Systems (ICUAS 2016). Arlington, VA (USA), June 2016. Print ISBN: 978-14673-9333-1

parameters depends on the source of the data, which are derived from theoretical computations, wind tunnel experiments and flight tests. To alleviate the effect of uncertainties, accurate data is used for modelling purposes. The covariance matrix is used to describe the effect of uncertainties in the estimation of the states as a function of time.

\section{A. Force Equations}

The equations describing the forces applied on the AEROSONDE RPAS are given by gravitational and propulsive forces and Newton's law of motions. Gravitational forces acting on the center of gravity of RPAS are given by:

$$
\begin{aligned}
& \left(\mathrm{F}_{\mathrm{x}}\right)_{\text {gravity }}=-\operatorname{mg\operatorname {sin}\vartheta } \\
& \left(\mathrm{F}_{\mathrm{y}}\right)_{\text {gravity }}=m g \cos \vartheta \sin \varphi \\
& \left(\mathrm{F}_{\mathrm{z}}\right)_{\text {gravity }}=\operatorname{mg} \cos \vartheta \cos \varphi
\end{aligned}
$$

where $\mathrm{F}$ is the force, $\vartheta$ is pitch, $\varphi$ is roll, $\mathrm{g}$ is acceleration due to gravity and $\mathrm{m}$ is mass of the RPAS. The propulsive forces are given by:

$$
\begin{gathered}
\left(F_{\mathrm{x}}\right)_{\text {engine }}=\mathrm{T} \cos \epsilon \\
\left(\mathrm{F}_{\mathrm{y}}\right)_{\text {engine }}=0 \\
\left(\mathrm{~F}_{\mathrm{z}}\right)_{\text {engine }}=-\mathrm{T} \sin \epsilon
\end{gathered}
$$

where $T$ is thrust supplied by engines and $\epsilon$ is angle between the horizontal and the mounted axis of the engines. The aerodynamic forces acting on the $\mathrm{x}, \mathrm{y}$ and $\mathrm{z}$ axes are denoted as $\mathrm{X}, \mathrm{Y}$ and $\mathrm{Z}$ respectively. The set of force equations are given by:

$$
\begin{gathered}
\mathrm{m}(\dot{\mathrm{u}}+\mathrm{qw}-\mathrm{rv})+\mathrm{u} * \dot{\mathrm{m}}=\mathrm{X}-\mathrm{mg} \sin \vartheta+\mathrm{T} \cos \epsilon \\
\mathrm{m}(\dot{\mathrm{v}}+\mathrm{ru}-\mathrm{pw})+\mathrm{v} * \dot{\mathrm{m}}=\mathrm{Y}+\mathrm{mg} \cos \vartheta \sin \varphi \\
\mathrm{m}(\dot{\mathrm{w}}+\mathrm{pw}-\mathrm{qu})+\mathrm{w} * \dot{\mathrm{m}}= \\
\mathrm{Z}+\mathrm{mg} \cos \vartheta \cos \varphi-\mathrm{T} \sin \epsilon
\end{gathered}
$$

\section{B. Moment Equations}

The kinematic moments in $\mathrm{x}, \mathrm{y}$ and $\mathrm{z}$ axes are expressed as:

$$
\begin{gathered}
\mathrm{H}_{\mathrm{x}}=\mathrm{pI}_{\mathrm{x}}-\mathrm{qI}_{\mathrm{xy}}-\mathrm{rI}_{\mathrm{xz}} \\
\mathrm{H}_{\mathrm{y}}=-\mathrm{pI}_{\mathrm{xy}}+\mathrm{qI}_{\mathrm{y}}-\mathrm{rI}_{\mathrm{yz}} \\
\mathrm{H}_{\mathrm{z}}=-\mathrm{pI}_{\mathrm{xz}}-\mathrm{qI}_{\mathrm{yz}}+\mathrm{rI}_{\mathrm{z}}
\end{gathered}
$$

where:

$$
\begin{gathered}
\mathrm{I}_{\mathrm{x}}=\iiint \mathrm{y}^{2}+\mathrm{z}^{2} \mathrm{dm} \\
\mathrm{I}_{\mathrm{y}}=\iiint \mathrm{x}^{2}+\mathrm{z}^{2} \mathrm{dm} \\
\mathrm{I}_{\mathrm{z}}=\iiint \mathrm{x}^{2}+\mathrm{y}^{2} \mathrm{dm} \\
\mathrm{I}_{\mathrm{xy}}=\iiint \mathrm{xy} \mathrm{dm} \\
\mathrm{I}_{\mathrm{yz}}=\iiint \mathrm{yz} d \mathrm{~m}
\end{gathered}
$$

$$
\mathrm{I}_{\mathrm{xz}}=\iiint \mathrm{xz} \mathrm{dm}
$$

The moments applied on the aircraft in the $\mathrm{x}, \mathrm{y}$ and $\mathrm{z}$ axes are denoted as $\mathrm{L}, \mathrm{M}$ and $\mathrm{N}$ respectively. The set of governing equations are given by:

$$
\begin{array}{r}
I_{x} \dot{p}+I_{x z} \dot{r}+\left(I_{z}-I_{y}\right) q r+I_{x z} q p=L \\
I_{y} \dot{q}+\left(I_{x}-I_{x}\right) p r+I_{x z}\left(r^{2}-p^{2}\right)=M \\
I_{z} \dot{r}+I_{x z} \dot{p}+\left(I_{y}-I_{x}\right) q p-I_{x z} q r=N
\end{array}
$$

\section{Modelling}

The ADM aerodynamic model includes inputs, aerodynamic parameters, coefficients, loads and outputs [11]. Aerodynamic parameters include wind axes velocity, dynamic pressure and the aerodynamic coefficients consist of lift coefficient, drag coefficient, side force coefficient, pitch moment coefficient, roll moment coefficient and yaw moment coefficient. The aerodynamic loads consist of aerodynamic forces and moments. Theoretically, the aerodynamic $(\mathrm{X}, \mathrm{Y}, \mathrm{Z})$ and propulsive terms (L, M, N) components are defined in a different approach according to fixed wing and rotary wing configurations. The aerodynamic forces and moments are assumed to be expressed as a multi-dimensional analytic function of the motion of the RPAS. The complexity and completeness of the aerodynamic database depends on the availability of aerodynamic derivatives (experimental and/or analytical methods). The first step towards dynamic modelling is to consider it as a rigid body with 6-DoF, followed by application of Newton's laws to the rigid body (RPAS platform). As previously mentioned, an Earth-fixed inertial frame makes analysis impractical since moments and products of inertia vary with time. This is not the case when a body-fixed reference frame is considered, where moments and products of inertia are constant. The AEROSONDE propulsion system includes the modelling of a piston engine and fixed pitch propeller [11]. The piston engine is modelled as a simple internal combustion engine based on the engine parameters that include fuel flow and engine power at sea-level, which are functions of RPM and manifold pressure. The throttle input to the piston engine is given as a function expressed as a fraction between the manifold pressure and atmospheric pressure. The propulsion system includes a fixed-pitch propeller, a piston engine and differential equations are used to solve for the engine shaft rotation speed. The AeroSim blockset provides the full list of aerodynamics coefficients and components including: moments, forces, wind axes velocity, dynamic pressure, lift coefficient, drag coefficient, side force coefficient, pitch moment coefficient, roll moment coefficient and yaw moment coefficient [12]. The groundspeed components in body axes are provided by the force equations. The effect of wind and turbulence on the AEROSONDE platform is included in the modelling. The wind-axes velocities, the time derivatives of airflow angles and the Mach number are used by additional aerodynamics and propulsion blocks. The implemented 6-DoF ADM has been validated in previous research with a 3 -DoF model [13]. The presented approach involves linear aerodynamics 
This is the author pre-publication version. This paper does not include the changes arising from the revision, formatting and publishing process. The final paper that should be used for referencing is:

F. Cappello, R. Sabatini and S. Ramasamy, “Aircraft Dynamics Model Augmentation for RPAS Navigation and Guidance.” Proceedings of IEEE International Conference on Unmanned Aircraft Systems (ICUAS 2016). Arlington, VA (USA), June 2016. Print ISBN: 978-14673-9333-1

in which the aerodynamic force and moment coefficients are computed using linear combinations of aerodynamic derivatives. The standardised aerodynamic coefficients are given below where the aerodynamic reference parameters (the parameters for which the aerodynamic coefficients were normalized). These include the reference wing chord, the wing span and the reference wing area [27]. The lift coefficient is computed using the expression:

$$
\begin{gathered}
\mathrm{C}_{\mathrm{L}}=\mathrm{C}_{\mathrm{L} 0}+\mathrm{C}_{\mathrm{L}}^{\alpha} \alpha+\mathrm{C}_{\mathrm{L}}^{\delta_{\mathrm{f}}} \delta_{\mathrm{f}}+\mathrm{C}_{\mathrm{L}}^{\delta_{\mathrm{e}}} \delta_{\mathrm{e}}+\frac{\mathrm{c}}{2 \mathrm{~V}_{\mathrm{a}}} \\
+\left(\mathrm{C}_{\mathrm{L}}^{\dot{\alpha}} \dot{\alpha}+\mathrm{C}_{\mathrm{L}}^{\mathrm{q}} \mathrm{q}\right)+\mathrm{C}_{\mathrm{L}}^{\mathrm{M}} \mathrm{M}
\end{gathered}
$$

The drag coefficient is computed using the expression:

$$
\begin{gathered}
\mathrm{C}_{\mathrm{D}}=\mathrm{C}_{\mathrm{D} 0}+\frac{\left(\mathrm{C}_{\mathrm{L}}-\mathrm{C}_{\mathrm{L} 0}\right)^{2}}{\pi \mathrm{eAR}}+\mathrm{C}_{\mathrm{D}}^{\delta_{\mathrm{f}}} \delta_{\mathrm{f}}+\mathrm{C}_{\mathrm{D}}^{\delta_{\mathrm{e}}} \delta_{\mathrm{e}} \\
+\mathrm{C}_{\mathrm{D}}^{\delta_{\mathrm{a}}} \delta_{\mathrm{a}}+\mathrm{C}_{\mathrm{D}}^{\delta_{\mathrm{r}}} \delta_{\mathrm{r}}+\mathrm{C}_{\mathrm{L}}^{\mathrm{M}} \mathrm{M}
\end{gathered}
$$

The side force coefficient is computed using the expression:

$$
\mathrm{C}_{\mathrm{Y}}=\mathrm{C}_{\mathrm{Y}}^{\beta} \beta+\mathrm{C}_{\mathrm{Y}}^{\delta_{\mathrm{a}}} \delta_{\mathrm{a}}+\mathrm{C}_{\mathrm{Y}}^{\delta_{\mathrm{r}}} \delta_{\mathrm{r}}+\frac{\mathrm{b}}{2 \mathrm{~V}_{\mathrm{a}}}\left(\mathrm{C}_{\mathrm{Y}}^{\mathrm{P}} \mathrm{p} \mathrm{C}_{\mathrm{Y}}^{\mathrm{r}} \mathrm{r}\right)
$$

The pitch moment coefficient is computed using the expression:

$$
\mathrm{C}_{\mathrm{m}}=\mathrm{C}_{\mathrm{m} 0}+\mathrm{C}_{\mathrm{m}}^{\alpha} \alpha+\mathrm{C}_{\mathrm{Y}}^{\delta_{\mathrm{r}}} \delta_{\mathrm{r}}+\frac{\mathrm{b}}{2 \mathrm{~V}_{\mathrm{a}}}\left(\mathrm{C}_{\mathrm{Y}}^{\mathrm{P}} \mathrm{p}+\mathrm{C}_{\mathrm{Y}}^{\mathrm{r}} \mathrm{r}\right)
$$

The roll moment coefficient is computed using the expression:

$$
\mathrm{C}_{\mathrm{l}}=\mathrm{C}_{\mathrm{l}}^{\beta} \beta+\mathrm{C}_{\mathrm{l}}^{\delta_{\mathrm{a}}} \delta_{\mathrm{a}}+\mathrm{C}_{\mathrm{l}}^{\delta_{\mathrm{r}}} \delta_{\mathrm{r}}+\frac{\mathrm{b}}{2 \mathrm{~V}_{\mathrm{a}}}\left(\mathrm{C}_{\mathrm{l}}^{\mathrm{P}} \mathrm{p}+\mathrm{C}_{\mathrm{l}}^{\mathrm{r}} \mathrm{r}\right)
$$

The yaw moment coefficient is computed using the expression:

$$
C_{n}=C_{n}^{\beta} \beta+C_{n}^{\delta_{a}} \delta_{a}+C_{n}^{\delta_{r}} \delta_{r}+\frac{b}{2 V_{a}}\left(C_{n}^{P} p+C_{n}^{r} r\right)
$$

where $C_{L}$ is the lift coefficient, $\alpha$ is the angle of attack, $\delta_{\mathrm{f}}$ is the error in flap settings, $\delta_{\mathrm{e}}$ is the error in pitch control settings, $\mathrm{c}$ is chord of the aerofoil, $\mathrm{V}_{\mathrm{a}}$ is the airspeed, $C_{D}$ is the drag coefficient, $e$ is the efficiency factor, $\mathrm{AR}$ is the aspect ratio, $\delta_{\mathrm{a}}$ is the error in aileron control settings, $\delta_{\mathrm{r}}$ is error in rudder control settings, $\mathrm{C}_{\mathrm{Y}}$ is the side slip coefficient, $\beta$ is the side slip angle, $C_{m}$ is the pitch moment coefficient, $\mathrm{C}_{\mathrm{l}}$ is the roll moment coefficient and $\mathrm{C}_{\mathrm{n}}$ is the yaw moment coefficient. The measurement vector is composed of 9 states: three measurements for each of position, velocity and attitude angles. The measurement vector is the differences between measurements provided by the augmenting sensor and the ones obtained from the Global Navigation Satellite System (GNSS). This vector is given by:

$$
\mathrm{z}=\left[\begin{array}{c}
\mathrm{P}_{\mathrm{ADM}}^{\mathrm{n}}-\mathrm{P}_{\mathrm{GNSS}}^{\mathrm{n}} \\
\mathrm{V}_{\mathrm{ADM}}^{\mathrm{n}}-\mathrm{V}_{\mathrm{GNSS}}^{\mathrm{n}} \\
\mathrm{A}_{\mathrm{ADM}}^{\mathrm{n}}-\mathrm{A}_{\mathrm{GNSS}}^{\mathrm{n}}
\end{array}\right]
$$

The diagonal of the measurement noise covariance matrix contains the variances of the ADM measurements. It describes kinematics properties and basic equations of motion of a generic RPAS.

\section{ADM AUGMENTATION}

Loose, tight and deep integration approaches are currently employed for multi-sensor data fusion at different levels including navigation solution, measurements and signal processing respectively [14]. GNSS, MicroElectromechanical System Inertial Measurement Unit (MEMS-IMU) and Vision-Based Navigation (VBN) Sensors are employed in the presented integrated architectures (Fig. 2). Position, Velocity and Attitude (PVA) measurements are obtained from MEMS-IMU and VBN sensors, while position and velocity data are providing by GNSS receivers. The ADM acts as a virtual sensor and provides PVA measurements. A conventional Extended Kalman Filter (EKF) and an advanced Unscented Kalman Filter (UKF) are used for multi-sensor data fusion [15-19]. Table I presents the different sensors used in the computation of the PVA best estimates.

TABLE I. SENSORS USED IN THE INTEGRATED ARCHITECTURES.

\begin{tabular}{|c|c|}
\hline RPAS PVA & Sensor \\
\hline \multirow{2}{*}{ Position } & GNSS \\
\cline { 2 - 2 } & MEMS-IMU \\
\cline { 2 - 2 } & VBN \\
\hline \multirow{2}{*}{ Velocity } & GNSS \\
\cline { 2 - 2 } & MEMS-IMU \\
\cline { 2 - 2 } Attitude & GNSS \\
\cline { 2 - 2 } & MEMS-IMU \\
\cline { 2 - 2 } & VBN \\
\hline \multirow{2}{*}{} & ADM \\
\hline
\end{tabular}

As four different sensors can be used for computing the best estimate, different integration modes are simulated. The first mode augments INS with ADM. The second one integrated INS with GNSS and VBN Sensors. The measurements from VBN sensors, GNSS and MEMS-IMU are used in VBN/IMU/GNSS (VIG) architecture. By including measurements from ADM, the VBN/IMU/GNSS/ADM (VIGA) system architecture is realised. EKF is used in both VIG and VIGA architectures. In UVIGA architecture, the EKF is replaced by an UKF. The VIG architecture uses VBN at $20 \mathrm{~Hz}$ and GPS at $1 \mathrm{~Hz}$ to augment the MEMS-IMU running at $100 \mathrm{~Hz}$.

The VIGA architecture includes the ADM (computations performed at $100 \mathrm{~Hz}$ ) to provide attitude channel augmentation. The integrated architectures consist of a number of subsystems, linked together by means of interfaces and software that are located in centralised/federated processors. Each of these subsystems may be capable of independent operation under some conditions but it is often beneficial if additional information 
This is the author pre-publication version. This paper does not include the changes arising from the revision, formatting and publishing process. The final paper that should be used for referencing is:

F. Cappello, R. Sabatini and S. Ramasamy, “Aircraft Dynamics Model Augmentation for RPAS Navigation and Guidance.” Proceedings of IEEE International Conference on Unmanned Aircraft Systems (ICUAS 2016). Arlington, VA (USA), June 2016. Print ISBN: 978-14673-9333-1

is derived from other subsystems. In the primary mode of operation, all subsystems contribute information to the integrating computer and the resulting total system has greater accuracy that any standalone subsystem. A key advantage of the integration schemes is that many of the

deterministic errors of the subsystem may be calibrated during the integration process by cross comparison of the subsystem outputs.

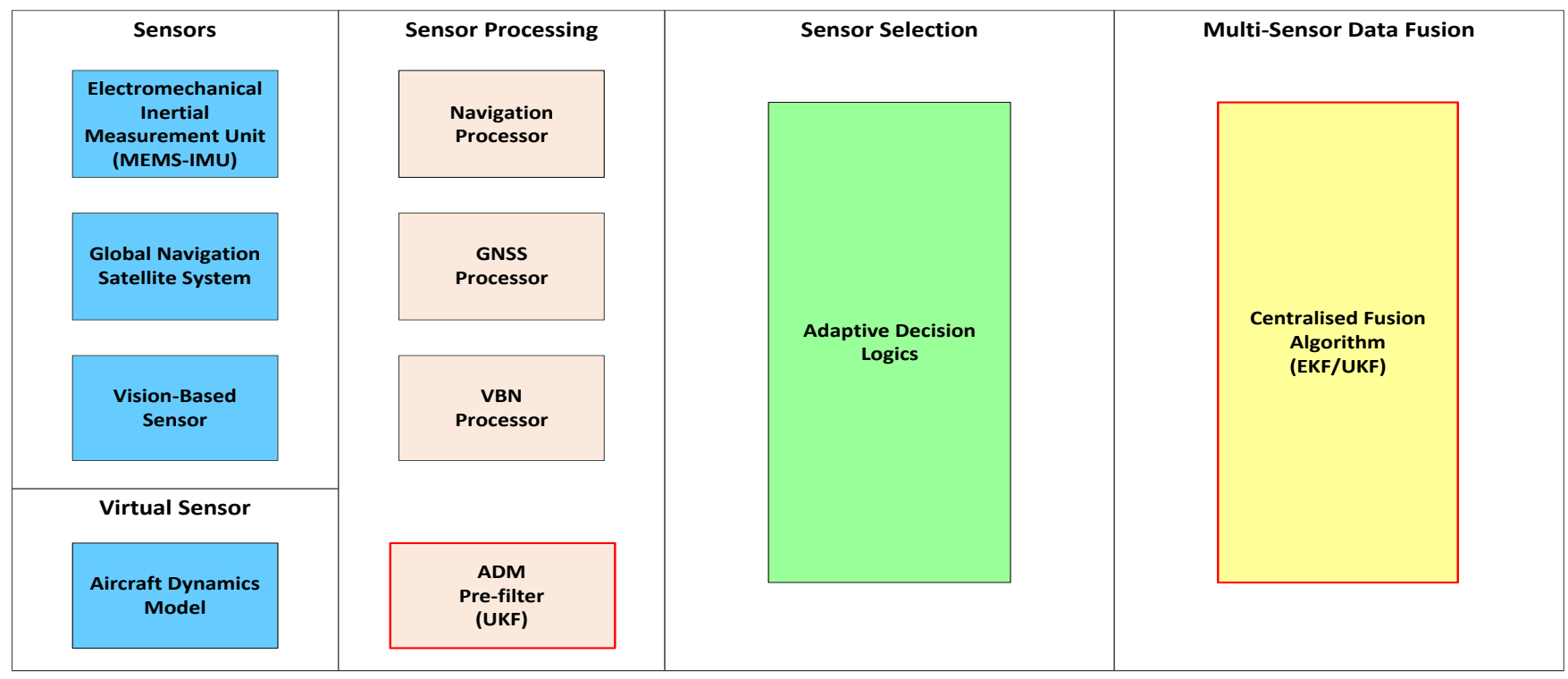

Fig. 2. Top level integration architecture.

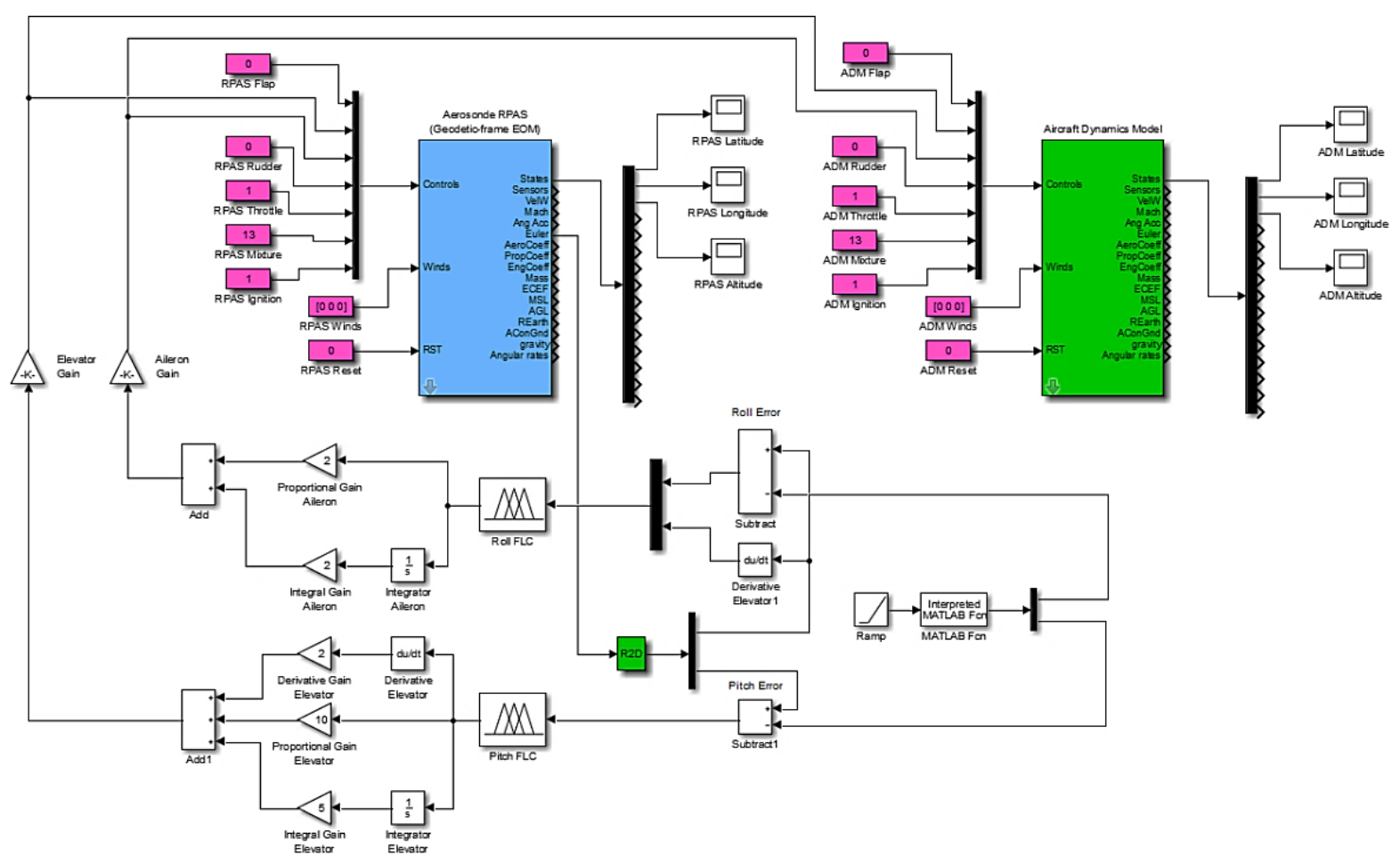

Fig.3. AEROSONDE SIMULINK model. 
This is the author pre-publication version. This paper does not include the changes arising from the revision, formatting and publishing process. The final paper that should be used for referencing is:

F. Cappello, R. Sabatini and S. Ramasamy, “Aircraft Dynamics Model Augmentation for RPAS Navigation and Guidance.” Proceedings of IEEE International Conference on Unmanned Aircraft Systems (ICUAS 2016). Arlington, VA (USA), June 2016. Print ISBN: 978-14673-9333-1

When one or more subsystems become non-operative (e.g., masking of GNSS satellites), the other system may continue to deliver satisfactory performance at higher level of accuracy than would otherwise be possible. The accuracy will degrade slowly, depending on the variability of the calibrated error sources, rather than suddenly as would occur with an uncalibrated sensor. After the degradations (GNSS, MEMS-IMU, VBN and ADM augmentation), loss of satellites (GNSS) or failures (all sensors) are restored, the system will once again return to full operation. Thus an integrated navigation system has a property of a robust operation with graceful degradation in the event of sensor non-operation and the ability to recover full capability should the non-operating sensor become operational. In addition, the inclusion of an ADM will increase the operational potential (accuracy and integrity) of this low-cost/weight and volume integrated navigation guidance and control system for small RPAS.

\section{Simulation CASE STUdy}

The multi-sensor architectures were tested by conducting a simulation case study. A sequence of flight manoeuvres representative of the AEROSONDE RPAS operational flight envelope was tested. The duration of the simulation was 1200 seconds. The SIMULINK model developed using innovative hybrid Fuzzy/PID controller is depicted in Fig. 3. A 3D trajectory plot of AEROSONDE RPAS flight phases for inputs provided in Table II is shown in Fig. 4.

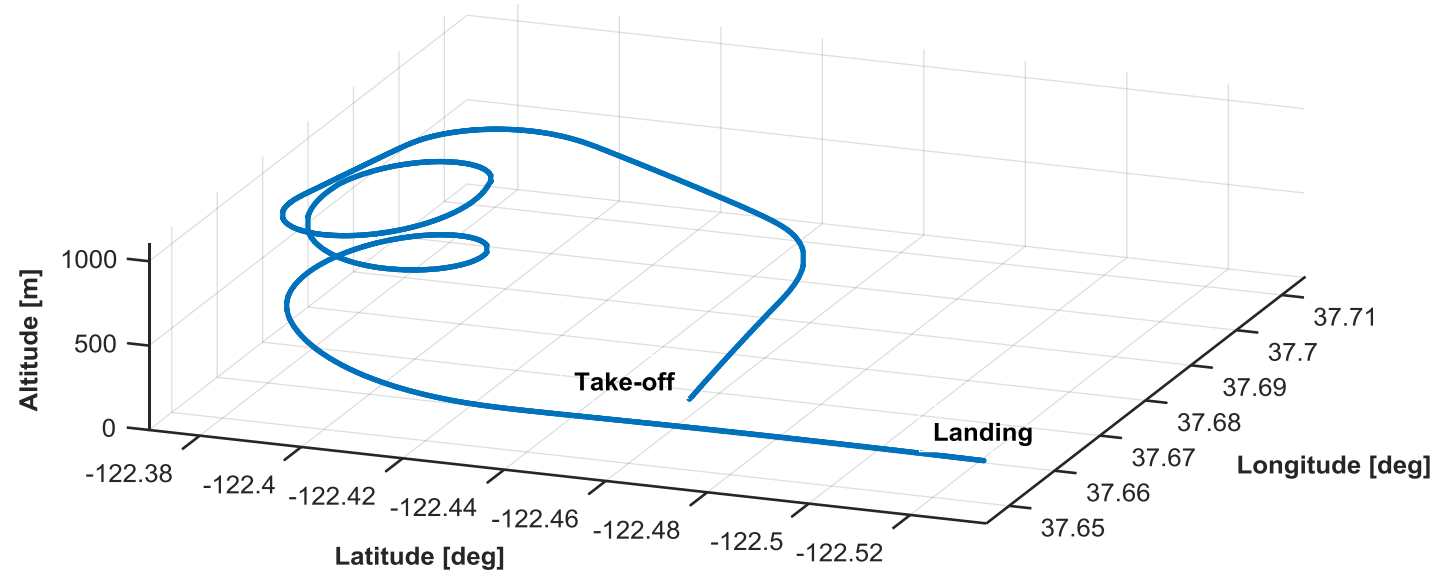

Fig. 4. 3D trajectory plot of AEROSONDE RPAS flight phases.

TABLE II. FLight MANOEUVRES AND CONTROL INPUTS.

\begin{tabular}{|c|c|c|c|}
\hline Flight Manoeuvres & $\begin{array}{c}\text { Required roll } \\
{[\mathbf{d e g}]}\end{array}$ & $\begin{array}{c}\text { Required pitch } \\
{[\mathbf{d e g}]}\end{array}$ & $\begin{array}{c}\text { Time } \\
{[\mathbf{s e c}]}\end{array}$ \\
\hline Straight climb (take-off) & 0 & 5 & 50 \\
\hline Left turning climb & 7 & 5 & 50 \\
\hline Straight climb & 0 & 5 & 100 \\
\hline Left turning climb & 3 & 5 & 100 \\
\hline Straight climb & 0 & 5 & 100 \\
\hline Left turning climb & 3 & 5 & 200 \\
\hline Medium Left turning Descent & 5 & -1 & 100 \\
\hline Medium Left turning Descent & 6 & -3 & 100 \\
\hline Hard Left turning Descent & 7 & -3 & 150 \\
\hline Slow Left turning Descent & 3 & -3 & 100 \\
\hline Straight descent (approach/landing) & 0 & -3 & 150 \\
\hline
\end{tabular}


This is the author pre-publication version. This paper does not include the changes arising from the revision, formatting and publishing process. The final paper that should be used for referencing is:

F. Cappello, R. Sabatini and S. Ramasamy, “Aircraft Dynamics Model Augmentation for RPAS Navigation and Guidance.” Proceedings of IEEE International Conference on Unmanned Aircraft Systems (ICUAS 2016). Arlington, VA (USA), June 2016. Print ISBN: 978-14673-9333-1

Values for mass, inertia, center of gravity and thrust errors have been chosen based upon judgment after performing numerous simulations [20-22]. The errors in gravity have been carefully chosen based on values available from the literature [20]. In order to obtain an ADM, which provides valid information to the navigation system to fly a performance-driven flight corridor such as continuous approach and landing, the various errors that contribute to the uncertainties have to be defined. The deviations are related to the Total System Error (TSE) of the GNC systems. The TSE primarily consists of the Path Definition Error (PDE), Flight Technical Error (FTE) / Path Steering Error (PSE) which is also associated with Display Error (DE) and Positioning Estimation Error (PEE)/Navigation System Error (NSE) [3]. Each control surface generates aerodynamic forces sufficient to manoeuvre the RPAS platform to achieve the mission. Each control surface is located at different points on the RPAS. Measurements errors are introduced in the control inputs of the dynamic model of the aircraft. The values of the parameters composing the ADM errors are presented in Table III.

TABLE III. ADM PARAMETRS AND ERRORS [20].

\begin{tabular}{|c|c|}
\hline Parameter & Value \\
\hline $\begin{array}{l}\text { Coefficients (on all } \\
\text { except the flap } \\
\text { coefficients) }\end{array}$ & $\mathrm{GN}(10 \%, 120 \mathrm{~s})$ \\
\hline Control input & $\begin{array}{c}\mathrm{WN}\left(0.02^{\circ}\right) \text { aileron, rudder, } \\
\text { elevator }\end{array}$ \\
\hline $\begin{array}{l}\text { Center of gravity error } \\
{[\mathrm{x}, \mathrm{y}, \mathrm{z}]}\end{array}$ & $\begin{array}{c}\text { Constant } \\
{[0.001,0.001,0.001] \mathrm{m}}\end{array}$ \\
\hline Mass error & $2 \%$ of true \\
\hline $\begin{array}{c}\text { Moment of inertia error } \\
{[\mathrm{Jx}, \mathrm{Jy}, \mathrm{Jz}, \mathrm{Jxz}]}\end{array}$ & $2 \%$ of true \\
\hline Thrust error & $\begin{array}{c}\text { Force, } 5 \% \text { of true, Moment } \\
5 \% \text { of true }\end{array}$ \\
\hline $\begin{array}{l}\text { Environmental } \\
\text { gravity error } 1 \sigma\end{array}$ & $36 \mu \mathrm{g}$ \\
\hline Air density error & $5 \%$ of true \\
\hline Speed of sound error & $5 \%$ of true \\
\hline $\begin{array}{c}\text { Wind } \\
\text { [North, East, Down] }\end{array}$ & {$[10 \mathrm{KN}, 10 \mathrm{KN}, 2 \mathrm{KN}]$} \\
\hline
\end{tabular}

Control inputs are control surfaces inputs which are, in other terms, deflection values of aileron, rudder and elevator; hence these errors are due to errors in measurement made from potentiometers. Other errors such as center of gravity, mass measurements or environmental errors are also modelled. Simulations were performed to analyse the sensitivity of the ADM as a virtual sensor when errors were injected in the input parameters. The nominal
ADM error is the error generated between the actual state of the aircraft and the ADM generated solution of the navigation state. In the architecture the best estimate is used to re-initillise the ADM at regular intervals. After performing an initilisation test (checking for consistency in ADM virtual sensor and RPAS dynamics outputs), the sensitivity of each output parameter (specifically attitudes) of the ADM is obtained when errors are injected into the input parameters. Fig. 5 shows the errors in ADM attitude angles as a result of errors injected in the input parameters (controls). Fig. 6 shows the analysis when a wind gradient are used in the simulation.
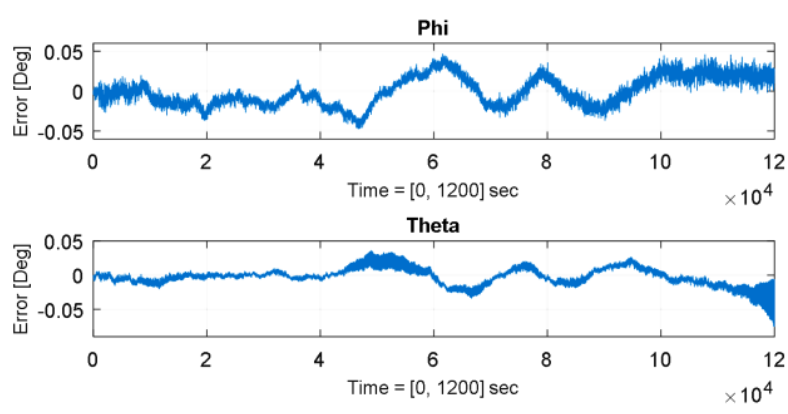

Psi

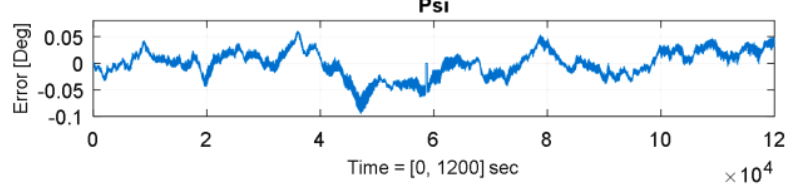

Fig. 5. Errors in ADM attitude anlges due to injected errors in input parameters.
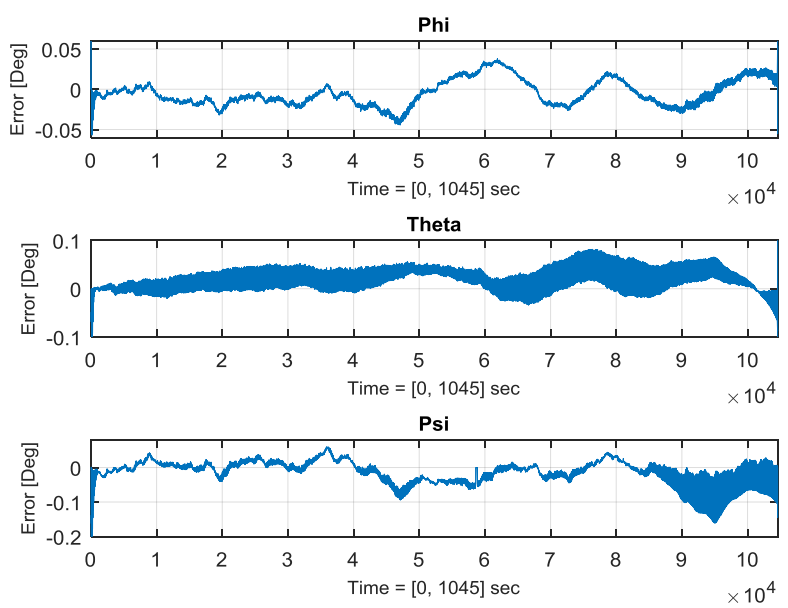

Fig. 6. Errors in ADM attitude anlges in the presence of wind.

The ADM in UVIGA system was tested especially in precision approach and landing phases of flight, which are the most demanding and critical phases, for determining its performance. The horizontal and vertical position accuracies with respect to nominal values and $1 \sigma$ and $2 \sigma$ 
This is the author pre-publication version. This paper does not include the changes arising from the revision, formatting and publishing process. The final paper that should be used for referencing is:

F. Cappello, R. Sabatini and S. Ramasamy, “Aircraft Dynamics Model Augmentation for RPAS Navigation and Guidance.” Proceedings of IEEE International Conference on Unmanned Aircraft Systems (ICUAS 2016). Arlington, VA (USA), June 2016. Print ISBN: 978-14673-9333-1

statistics are obtained and compared. These results indicate that the ADM improves the overall navigation solution for short periods of time in addition to providing a better overall system performance. The UVIGA horizontal and vertical channel ADM results are depicted in Fig. 7 and 8 respectively. Table IV provides the attitude error statistics of the navigation system architectures. During the initial VIGA simulation runs, it is demonstrated that the ADM data cannot be used effectively without being re-initialised regularly. As a result of using a pre-filtered ADM, there is an improvement in the ADM validity time as tabulated in Table V.

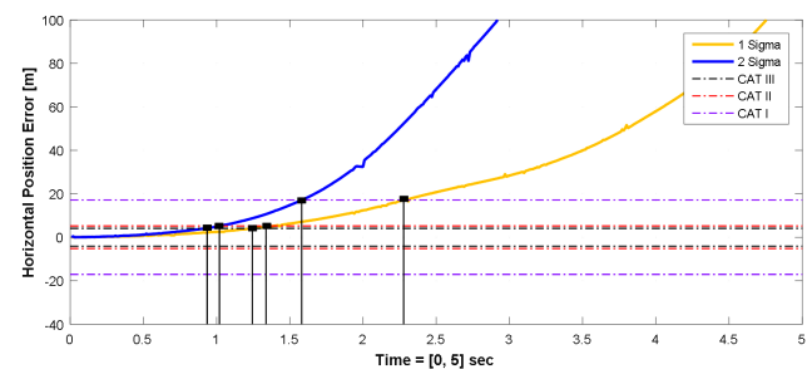

Fig. 7. UVIGA horizontal channel - ADM precision approach and landing performance.

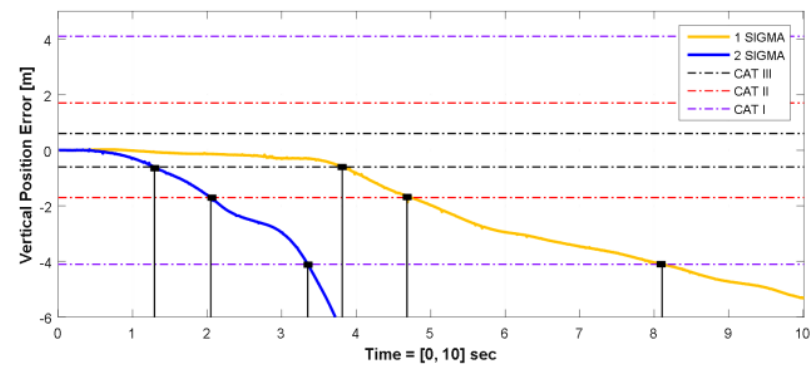

Fig. 8. UVIGA horizontal channel - ADM precision approach and landing performance.

TABLE IV. ATTITUDE ERRor STATISTICS.

\begin{tabular}{|c|c|c|c|c|c|c|}
\hline \multirow{2}{*}{$\begin{array}{c}\text { Sensor } \\
\text { List }\end{array}$} & \multicolumn{2}{|c|}{$\begin{array}{c}\text { Theta }(\boldsymbol{\theta}) \\
{[\mathbf{d e g}]}\end{array}$} & \multicolumn{2}{c|}{$\begin{array}{c}\text { Phi }(\boldsymbol{\phi}) \\
{[\mathbf{d e g}]}\end{array}$} & \multicolumn{2}{c|}{$\begin{array}{c}\text { Psi }(\boldsymbol{\Psi}) \\
{[\mathbf{d e g}]}\end{array}$} \\
\cline { 2 - 7 } & $\boldsymbol{\mu}$ & $\boldsymbol{\sigma}$ & $\boldsymbol{\mu}$ & $\boldsymbol{\sigma}$ & $\boldsymbol{\mu}$ & $\boldsymbol{\sigma}$ \\
\hline VIG & 0.17 & 2.29 & 1.20 & 2.12 & -0.85 & 2.19 \\
\hline VIGA & -0.08 & 2.06 & 0.91 & 2.17 & $-1.7 \mathrm{E}-04$ & 1.43 \\
\hline UVIGA & -0.05 & 2.00 & 0.91 & 2.12 & $-1.7 \mathrm{E}-04$ & 1.31 \\
\hline
\end{tabular}

TABLE V. ADM VALIDITY TIME.

\begin{tabular}{|c|c|c|}
\hline \multirow{2}{*}{$\begin{array}{c}\text { Accuracy } \\
\text { Threshold }\end{array}$} & \multicolumn{2}{|c|}{ ADM Validity Time [sec] } \\
\cline { 2 - 3 } & VIGA & UVIGA \\
\hline CAT III & 13 & 23 \\
\hline CAT II & 49 & 81 \\
\hline CAT I & 105 & 126 \\
\hline
\end{tabular}

Compared with the VIGA solution, a significant improvement in the ADM validity time is obtained with the UVIGA system as shown in Table XI. In particular, the validity times before the solution exceeds CAT I, CAT II and CAT III limit are $126 \mathrm{sec}, 81 \mathrm{sec}$ and $23 \mathrm{sec}$ respectively (the VIGA was compliant with CAT I up to $105 \mathrm{sec}$, CAT II up to $49 \mathrm{sec}$ and CAT III up to sec to 13 sec). Converting VIG and VIGA error statistics to the corresponding RMS (95\%) values, it is evident that the ADM virtual sensor contributes to a moderate reduction in the overall attitude error budget in all flight phases.

\section{CONCLUSIONS}

An Aircraft Dynamics Model (ADM) virtual sensor was presented for Remotely Piloted Aircraft System (RPAS) navigation and guidance. The developed knowledge-based module was used to augment the navigation state vector by predicting RPAS flight dynamics. ADM augmentation of GNSS, MEMS-IMUs and VBN sensor was described. The ADM virtual sensor was adopted in a variety of multisensor data fusion architectures employing EKF and UKF. The adoption of a pre-filtered UKF improved the ADM validity time. A case study was performed using the AEROSONDE RPAS and the results showed that the proposed integration schemes can achieve high horizontal/vertical position accuracies, with a significant improvement compared to stand-alone GNSS and integrated GNSS/INS systems. The UKF based system showed the best performance in attitude data accuracy in addition to achieving the highest ADM validity time (validity time of $126 \mathrm{sec}$ before exceeding CAT I limit). Future research will focus on a detailed sensitivity and failure mode analysis addressing the various errors affecting the RPAS states and sensor measurements. Furthermore, the investigation of the potential synergies obtained by integrating RPAS navigation with GNSS space, ground and avionics based integrity augmentation systems [23, 24] will be performed.

\section{REFERENCES}

[1] M.J. Logan, J. Chu, M.A. Motter, D.L. Carter, M. Ol and C. Zeune, "Small UAV Research and Evolution in Long Endurance Electric Powered Vehicles", AIAA Infotech @ Aerospace 2007 Conference and Exhibit, Rohnert Park, California, USA, pp. 7-10, 2007.

[2] R. Melnyk, D. Schrage, V. Volovoi and H. Jimenez, "A Third-Party Casualty Risk Model for Unmanned Aircraft System Operations", Reliability Engineering \& System Safety, Vol. 124, pp. 105-116, 2014.

[3] ICAO, 2013-2028 Global Air Navigation Capacity \& Efficiency Plan, Doc 9750, Draft 2014-2015, Triennium Edition, Montreal, Canada, 2014.

[4] FAA, Integration of Civil Unmanned Aircraft Systems (UAS) in the National Airspace System (NAS) Roadmap, Federal Aviation Administration (FAA), 2013.

[5] S. Ramasamy, R. Sabatini, A. Gardi and T. Kistan, "Next Generation Flight Management System for Real-Time Trajectory Based Operations", Applied Mechanics and Materials, vol. 629, Trans Tech Publications, Switzerland, pp. 344-349, 2014. DOI: 10.4028/www.scientific.net/AMM.629.344

[6] R. Sabatini, M. Richardson, C. Bartel, T. Shaid and S. Ramasamy, "A Low-cost Vision Based Navigation System for Small Size Unmanned Aerial Vehicle Applications", Journal of Aeronautics and Aerospace Engineering, Vol. 2, No. 2, pp. 1-16, 2013. 
This is the author pre-publication version. This paper does not include the changes arising from the revision, formatting and publishing process. The final paper that should be used for referencing is:

F. Cappello, R. Sabatini and S. Ramasamy, “Aircraft Dynamics Model Augmentation for RPAS Navigation and Guidance.” Proceedings of IEEE International Conference on Unmanned Aircraft Systems (ICUAS 2016). Arlington, VA (USA), June 2016. Print ISBN: 978-14673-9333-1

[7] F. Cappello, S. Ramasamy and R. Sabatini, "Low-cost Multi-Sensor Data Fusion for Unmanned Aircraft Navigation and Guidance", International Journal of Science and Engineering Investigations, vol. 4, no. 43, pp. 1-10, 2015.

[8] M. Tad and J. Vagners, "Wide-Scale Use of Long-Range Miniature Aerosondes over the World's Oceans", National Oceanic and Atmospheric Administration, Washington DC, USA, 2000.

[9] T. McGeer and G.J. Holland. "Small Autonomous Aircraft for Economical Oceanographic Observations on a Wide Scale", Oceanography, vol. 6, issue 3, pp. 129-135, 1993.

[10] G.J. Holland, P.J. Webster, J.A. Curry, G. Tyrell, D. Gauntlett, G. Brett, J. Becker, R. Hoag and W. Vaglienti, "The Aerosonde Robotic Aircraft: A New Paradigm for Environmental Observations", Bulletin of the American Meteorological Society, vol. 82, issue 5, pp. 889-901, 2001.

[11] Unmanned Dynamics LLC, AeroSim Blockset, User's Guide, Version 1.01, Hood River, OR, USA, 2006. Available online: http://www.udynamics.com.

[12] Unmanned Dynamics LLC, AeroSim Blockset, Version 1.2, Hood River, OR, USA. Available online: http://www.udynamics.com.

[13] M.T. Burston, R. Sabatini, R. Clothier, A. Gardi and S. Ramasamy, "Reverse Engineering of a Fixed Wing Unmanned Aircraft 6-DoF Model for Navigation and Guidance Applications", Applied Mechanics and Materials, vol. 629, Trans Tech Publications, pp. 164-169, 2014. DOI: 10.4028/www.scientific.net/AMM.629.164

[14] Y. Tawk, P. Tomé, C. Botteron, Y. Stebler and P. Farine, "Implementation and Performance of a GPS/INS Tightly Coupled Assisted PLL Architecture using MEMS Inertial Sensors", Sensors, vol. 14, no. 2, pp. 3768-3796, 2014.

[15] F. Cappello, S. Ramasamy and R. Sabatini, "Low-Cost Multi-Sensor Data Fusion for Unmanned Aircraft Navigation and Guidance", Journal of Science and Engineering Investigations, vol. 4, no. 43, pp. $1-10,2015$.

[16] E. Wan and R. Van Der Merwe, "The Unscented Kalman Filter for Nonlinear Estimation", Adaptive Systems for Signal Processing Communications, and Control Symposium, Lake Louise, Alberta, Canada, pp. 153-158, 2000.

[17] S.J. Julier and J.K. Uhlmann, "New Extension of the Kalman Filter to Nonlinear Systems", AeroSense'97, Signal Processing, Sensor Fusion, and Target Recognition VI, July 28, 1997. DOI: 10.1117/12.280797.

[18] S.J. Julier and J.K. Uhlmann, "Unscented Filtering and Nonlinear Estimation”, Proceedings of IEEE, vol. 92, no. 3, pp. 401-422, March, 2004.

[19] L.A. Sandino, M. Bejar, K. Kondak and A. Ollero, "A Square-Root Unscented Kalman Filter for Attitude and Relative Position Estimation of a Tethered Unmanned Helicopter", International Conference on Unmanned Aircraft Systems (ICUAS), pp. 567-576, June, 2015.

[20] T.S. Bruggemann, "Investigation of MEMS Inertial Sensors and Aircraft Dynamic Models in Global Positioning System Integrity Monitoring for Approaches with Vertical Guidance", Unpublished $\mathrm{PhD}$ thesis, Queensland University of Technology, School of Engineering, 2009.

[21] M. Koifman and I. Bar-Itzhack, "Inertial Navigation System aided by Aircraft Dynamics", IEEE Transaction on Control Systems Technology, vol.7, 1999.

[22] K. Lievens, J. Mulder and P. Chu, "Single GPS Antenna Attitude Determination of a Fixed Wing Aircraft aided with Aircraft Aerodynamics", AIAA Guidance, Navigation and Control Conference, San Francisco, California, USA, 2005.

[23] R. Sabatini, T. Moore and C. Hill, "Avionics Based GNSS Integrity Augmentation for Mission- and Safety-Critical Applications", Paper presented at $25^{\text {th }}$ International Technical Meeting of the Satellite Division of the Institute of Navigation: ION GNSS-2012, Nashville (Tennessee), September 2012.

[24] R. Sabatini, T. Moore, C. Hill and S. Ramasamy, "Assessing Avionics-Based GNSS Integrity Augmentation Performance in UAS 